\title{
The extrinsic influence of carbon fibre reinforced plastic laminates to strengthen steel structures
}

\author{
A K PATNAIK ${ }^{1}$, C L BAUER ${ }^{2}$ and T S SRIVATSAN ${ }^{3 *}$ \\ ${ }^{1}$ Department of Civil Engineering, The University of Akron, Akron, \\ Ohio 44325 3905, USA \\ ${ }^{2}$ Ulteig Engineering, Inc., 1412, Basin Avenue, Bismarck, North Dakota 58504, \\ USA \\ ${ }^{3}$ Division of Materials Science and Engineering, Department of Mechanical \\ Engineering, The University of Akron, Akron, Ohio 44325 3903, USA \\ e-mail: tsrivatsan@uakron.edu
}

\begin{abstract}
The intrinsic advantages of strengthening the steel-based structures by the use of fibre reinforced plastic (FRP) material have not yet been fully exploited. In this paper, a succinct overview of recent studies made to enhance the strength of steel beams using FRP laminates is presented. The results presented and discussed in this paper were obtained by closely studying the behaviour of steel beams strengthened with carbon FRP material. An attempt is made to succinctly summarise the findings for two different types of strengthening of the steel beams using carbon FRP laminates. The first type of beams focuses on enhancing the strength of steel in flexure while the second focuses on increasing the shear strength of the beams. Three beams were designed so as to cause them to fail in flexure. Of the beams studied, two were strengthened using carbon FRP strips attached to the tension flange. One of the beams was tested to facilitate comparison of their behaviour to the two beams which are strengthened in flexure. Three other beams were designed such that they failed predominantly in shear. Of these three, two were strengthened with carbon FRP strips attached to the webs while the third beam was used as a control beam for the purpose of drawing comparisons. Preliminary results revealed a noticeable increase in the strength for both the flexure strengthened beams and the beams strengthened in shear. The observed increase in shear strength of the beams was $26 \%$ while the increase in strength for the beams tested in flexure was $15 \%$. This study convincingly shows that it is possible to strengthen steel beams using carbon FRP laminates in both flexure and in shear.
\end{abstract}

Keywords. Fibre reinforced polymer; steel beams; shear, flexure and strengthening.

*For correspondence 


\section{Introduction}

A large majority of the highways and bridges in the United States were built during the decades of the 1950s and 1960s as part of the Dwight D. Eisenhower System of Interstate and Defense Highways (West 2001). Since that time, i.e. during the last sixty years, the infrastructure that was established did experience a gradual deterioration and/or decay in performance at a rate faster than it can be repaired or replaced. The observed deterioration is far more noticeable or evident in the eastern region of United States where many of the roads and bridges in this region are in excess of 100 years of age. The Federal Highway Administration (FHA) has a total of 596,800 bridges on the National Bridge Inventory (NBI) at the end of 2006. Approximately 74,000 of these bridges were classified as being either structurally deficient or functionally obsolete (Memmott 2007). The huge cost of repairing and/or simply replacing the deficient bridges coupled with its concurrent impact on traffic disruption during the course of replacement does make repair and rehabilitation a more feasible option.

The placement of a concrete bridge deck over steel is a common design used for bridges in the United States. However, these bridges require regular maintenance, such as, painting to ensure their prolonged serviceability. Of course, the maintenance is expensive from the standpoint of both material cost and labour cost. As a result, maintenance of these structures has often been neglected causing environmental degradation in the form of corrosion of the steel beams to becoming a problem of alarming concern. More than $43 \%$ of the bridges that were classified as being functionally obsolete were made from steel (Tavakkolizadeh \& Saadatmanesh 2003). Also, many of the older bridges that have been through prior maintenance do suffer from a lack of strength to support the currently used load (HS25) imposed by the movement of traffic. A common method for repairing the deteriorated or structurally deficient steel beams is to either weld or bolt steel plates to the bottom flange of the beams. However, this method is labour and cost-intensive coupled with the need for on-site welding and drilling operations. Once repaired, the steel beams would require periodic maintenance to prevent the occurrence of corrosion. It is to be noted that the addition of steel plates do add self-weight to the structure. This has provoked the thought of using epoxy bonding fibre reinforced plastic (FRP) to deteriorated steel beams as an economically viable rehabilitation and strengthening technique.

Several types of FRP are currently available to provide strength to metal structures. Due to its initial success in strengthening concrete structures, glass fibre reinforced polymer (GFRP) is a readily available and least expensive type of Fibre Reinforced Plastics. However, other types of fibre, such as, carbon and Kevlar have also found use to make FRP, and these have been commonly used in recent years. This has enabled in a gradual lowering of the price of these materials. The carbon fibre reinforced polymers (CFRP) are considered to be the best suited for the purpose of strengthening of steel structures. This is essentially due to the higher elastic modulus of the CFRP over other commonly available types of FRP. Most noticeably, many types of CFRP are able to achieve an elastic modulus that is either similar to or greater than that of steel.

During the last two decades, several successful studies have been conducted in the retrofit and repair of concrete and masonry structure using FRP. This has resulted in the increasing use of FRP in concrete structures to gain acceptance by the engineering community. However, to date, the amount of research in the area of retrofitting and repair of steel-based structures continues to be limited (West 2001; Miller 2000; Tavakkolizadeh \& Saadatmanesh 2003; Miller et al 2001; Karbhari \& Shulley 1995; Ammar 1996). Not all of the studies done by others is mentioned in this paper. However, a few notable ones are highlighted. In one study 
(Ammar 1996), the deteriorated steel bridge girders were retrofitted with the objective of regaining moment strength. Preliminary test results indicated that retrofitting steel beams with CFRP (a) does increase the overall moment strength, (b) helps in the recovery of stiffness lost due to corrosion, and (c) helps to control the propagation of cracks arising from fatigue (Miller et al 2001). A companion study (Tavakkolizadeh \& Saadatmanesh 2003) showed that bonding of the CFRP to the tension flange of the steel-concrete composite girders did increase the ultimate load carrying capacity. An observation resulting from a few studies investigating the use of FRP to strengthen and repair steel structure is that it can be used as an effective alternative to the traditional methods of strengthening. A few of the studies reported in the published literature have attempted to investigate the flexural strengthening of steel beams reinforced with FRP. However, none of these studies have attempted to strengthen the steel beams in shear and study their mechanical behaviour.

In this paper, the behaviour of steel beams strengthened with strips of carbon FRP is presented and discussed. Two types of strengthening were essentially used: (a) To increase the shear strength. (b) To increase flexural strength of the beams.

Two steel beams were strengthened with carbon FRP strips attached to the tension flange. The third beam was tested to facilitate drawing comparison with the behaviour of the other two beams strengthened in flexure. The other three beams were designed to fail in shear. Two of these beams were strengthened with carbon FRP strips attached to the web and the third beam of this set was used as the control beam for the purpose of facilitating comparison. The materials used and chosen, the test method(s), intrinsic details of the test beams, test results, and a brief discussion of the results obtained are outlined in this paper.

\section{Materials}

\subsection{Carbon fibre reinforced plastic (CFRP)}

A unidirectional pull-form of epoxy-carbon composite laminate strip was used to strengthen the steel test beams. The CFRP strips were part of the Tyfo ${ }^{\mathrm{R}} \mathrm{UC}$ Composite Laminate Strip system provided by Fyfe Co. LLC (USA). The manufacturer specified tensile strength was $2790 \mathrm{MPa}$, ductility, i.e. elongation at break was $1.8 \%$, and tensile modulus was $155.1 \mathrm{GPa}$, respectively. The CFRP strips were $1.4 \mathrm{~mm}$ in thickness $(t)$ and $51 \mathrm{~mm}$ in width $(w)$ and were made available in rolls up to $150 \mathrm{~m}$ in length. A total of 10 coupons cut to a length of $610 \mathrm{~mm}$ were tested in the materials testing laboratory and the average ultimate tensile strength was found to be $2690 \mathrm{MPa}$. The strain and load data were collected during the tension tests and the average elastic modulus in tension was found to be $148 \mathrm{GPa}$. The tensile properties were determined in conformance with the procedures outlined in the standard ASTM D 3039. The values obtained were in reasonable agreement with the values provided by the manufacturer.

\subsection{Steel}

The two different types of beams used in this study were built up from steel plate, sheet, and bar elements. Bearing stiffeners were used at both the loading and support points to prevent the occurrence of localised failures.

(a) The beams designed to fail in flexure had the following dimensions: (i) a flange width of $152.5 \mathrm{~mm}$, (ii) a flange thickness of $9.5 \mathrm{~mm}$, (iii) a web height of $305 \mathrm{~mm}$, (iv) a web thickness of $9.5 \mathrm{~mm}$, and (v) an overall depth of $324 \mathrm{~mm}$. 
(b) The beams designed to fail in shear had the following dimension (a) a flange width of $254 \mathrm{~mm}$, (b) a flange thickness of $12.7 \mathrm{~mm}$, (c) a web height of $330 \mathrm{~mm}$, (d) a web thickness of $3.2 \mathrm{~mm}$, and (e) a total depth of $355.5 \mathrm{~mm}$.

Overall, the two types of beam specimens were $3.35 \mathrm{~m}$ in length, with support points located $100 \mathrm{~mm}$ from the beam ends. The loading points were effectively $305 \mathrm{~mm}$ from the midspan of the beam.

The portions of the steel used to fabricate the test beams were cut into coupons for the purpose of testing. Specifically, rectangular tension coupons were produced from the material used for the flanges of the flexural beams and similar coupons were made from the material used for the web of the shear failure beams. The coupons from the flange material of the flexural beams measured $9.5 \mathrm{~mm}$ in thickness by $51 \mathrm{~mm}$ in width and $610 \mathrm{~mm}$ in length. An average yield strength of $320 \mathrm{MPa}$ and an elastic modulus of $203 \mathrm{GPa}$ was obtained. The coupons from the web material of the shear beams measured $3.2 \mathrm{~mm}$ in thickness by $51 \mathrm{~mm}$ in width and $610 \mathrm{~mm}$ in length. An average yield strength of $225 \mathrm{MPa}$ and an elastic modulus of $196 \mathrm{GPa}$ was obtained. The mechanical tests on the steel specimens were done in accordance with procedures outlined in the standard ASTM E 8 (ASTM Standard E8-01, 2001).

\subsection{The adhesive}

The adhesive that was used to enable the CFRP strips to adhere to the steel beams was Araldite ( AW-8535/Hardener HW-8535, a two-component epoxy adhesive produced by Vantico Inc [USA]. When mixed in proper proportions, the two-component epoxy adhesive becomes a high viscosity paste that facilitates metal-to-metal bonding. This epoxy is capable of bonding to oily metals while concurrently offering excellent resistance to sagging. The high viscosity of the epoxy necessitated the need for a pneumatic dispensing gun to ensure effective mixing and dispensing of the epoxy at room temperature. At ambient temperature, the handling time was $5.5 \mathrm{~h}$ and the minimum cure time was $16 \mathrm{~h}$. The manufacturers specified lap shear strength of the epoxy is $17.2 \mathrm{MPa}$. This value was obtained from the lap shear tests that were conducted using coupons made from acid-etched aluminum that was bonded to acid-etched aluminum. In this study, the double lap shear coupons were made with the purpose of determining the bond strength of the epoxy between the CFRP strips and steel. A lap shear strength of $12.8 \mathrm{MPa}$ was obtained from these tests. Surface preparation of the lap shear coupons was nearly identical to the surface preparation used for strengthening of the steel beams.

\section{Experimental set-up}

\subsection{Specimen details}

A schematic showing sectional details of the test beam is provided in figure 1. Both types of test beams were of the same overall length, and supported and loaded at the same points. A typical elevation of the test beams is as shown in figure 2 .

\subsection{The CFRP strengthening system}

In an attempt to ensure proper bonding between the steel metal and the strips of CFRP, surface preparation of the steel was essential. Initially, the mill scale was removed to ensure that 

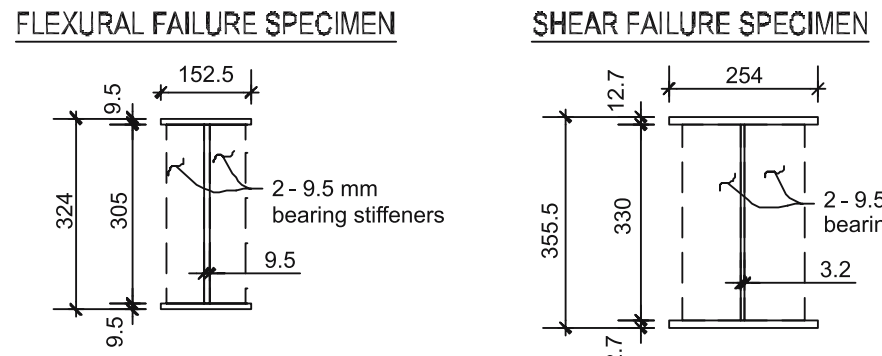

NOTE: All dimensions in mm

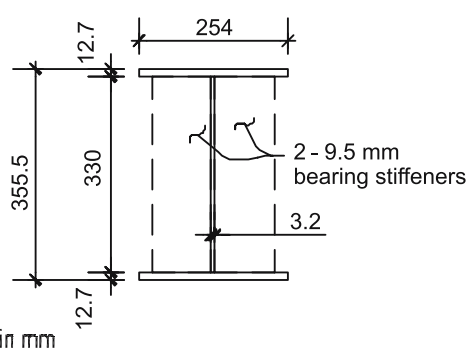

Figure 1. Typical sectional details of test beams.

the bond continued to remain intact even after the steel had yielded. Also, the surface was roughened with the purpose of maximizing bond strength. These two tasks were accomplished on a belt sander having a coarse grit sanding belt. While most certainly effective, use of the belt sander is both tedious and time consuming. Following surface preparation of the steel surfaces, the surfaces of the steel samples were blown free of debris using a high pressure air nozzle, then rinsed in water, and subsequently wiped with acetone to remove residual oil and grease material on the surface.

The CFRP strips were first cut to the required length. The strips were then pre-abraded on one side and did not require any sanding. Since the strips were only $51 \mathrm{~mm}$ in width, they were carefully assembled to form 'plates' prior to attaching them onto the beams (figure 3). The plates were then assembled by hot gluing the strips on a wooden lathe, while keeping the pre-abraded side exposed. Subsequently, the surfaces were blown free of debris using a high pressure air nozzle, rinsed in water, and wiped with acetone to remove traces of residual oil and greasy material on the surface.

Following preparation of the surfaces of both steel and CFRP, the epoxy was carefully dispensed on the steel surface using a pneumatic gun. The epoxy was spread in a thin layer over the steel surface using a typical putty knife. The CFRP plate was then placed on the steel surface and clamped to squeeze-out the excess epoxy. The specimens were then cured for a minimum of 24 hours before removing the clamps.

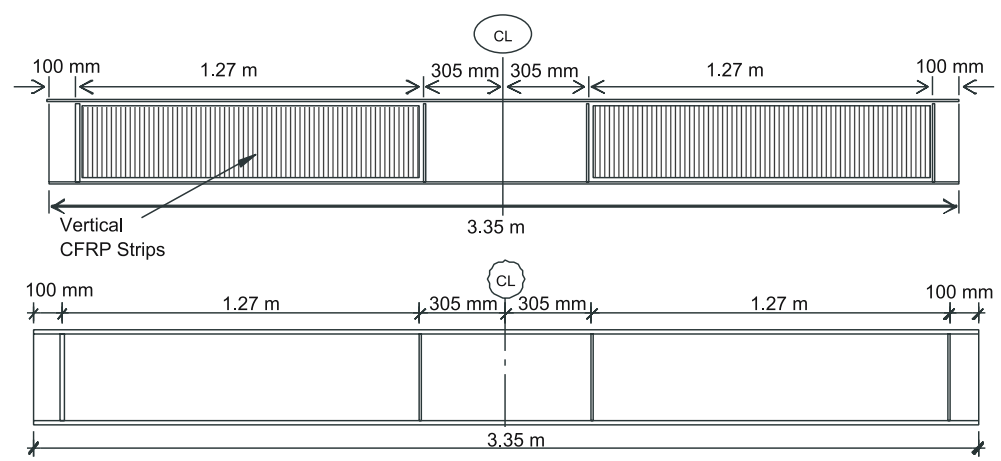

Figure 2. Typical elevation of the shear strengthened test beams. 


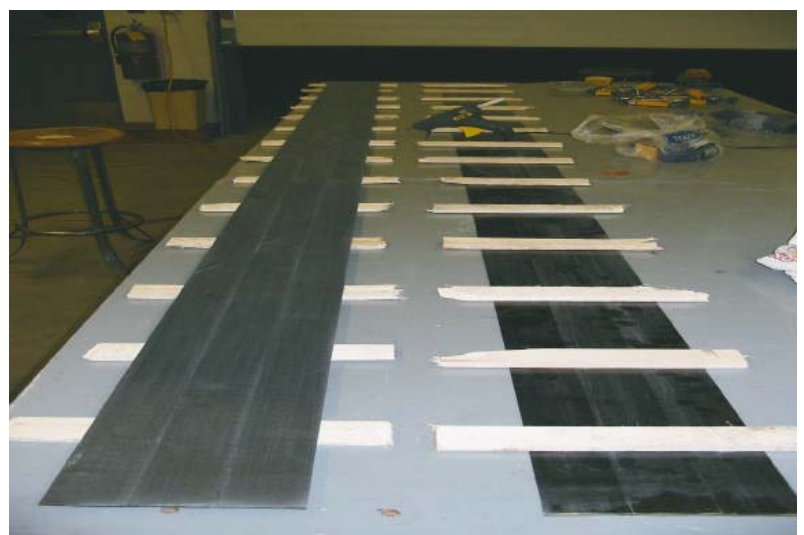

Figure 3. The CFRP laminates prior to installation.

(i) The moment failure beam specimens were strengthened by covering the tension flange with one layer of the CFRP strips running the length of the beam from support to support.

(ii) The shear failure beam specimens were strengthened by covering each side of the web with one layer of the CFRP strips running from the support point to the load point on both ends of the beam specimen. The CFRP strips were attached side-by-side and transverse to the axis of the beam.

\subsection{Instrumentation for test beams}

Each beam specimen was instrumented with fourteen strain gages having a $120 \mathrm{ohm}$ resistance. The mid-span deflections were monitored and recorded at discrete points. The strain, deflection, and load data were collected at periodic intervals. The layout of the strain gages varied for both the flexural failure specimens and the shear failure specimens (figure 4).

(i) The flexural failure specimen had a total of 8 strain gages positioned along the centerline of the beam.

(ii) The majority of strain gages for the shear failure beam were distributed on the web in a three-gage 45 degree rosette. The rosettes were placed at mid-height of the web. One gage was on the top side of the upper flange while two gages were on the bottom side of the lower flange at the quarter span length.

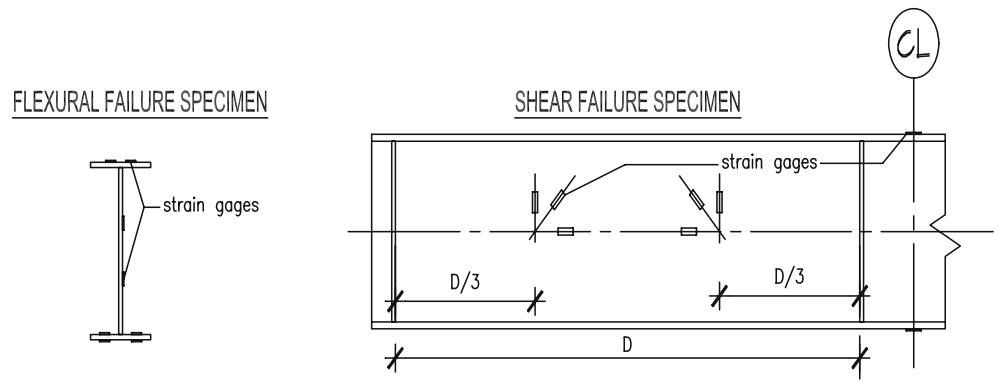

Figure 4. A typical layout of strain gages. 
The remaining eight gages were placed at the centerline of the beam. Two of these gages were fixed on the top side of the top flange. Two gages on the web were located at one-third the web height from each flange. Two gages were fixed on the top side of the bottom flange; and two gages were fixed on the bottom side of the bottom flange.

The shear failure beam had one gage on the top side of the top flange and one gage on the bottom side of the bottom flange along the centerline. The remaining twelve gages were arranged in three-gage 45-degree rosettes and placed at the center of the web at points onethird the distance between the bearing stiffeners (figure 4).

Throughout the mechanical testing, the strain data was gathered at discrete points using a Data Acquisition System (Model: Quatech) interfacing with a PC having Daisylab software. The midspan deflections were monitored and recorded at discrete points using a Linear Variable Differential Transducers (LVDT) in conjunction with a data acquisition system.

\section{The test set-up}

\subsection{Experimental set-up}

Four point bend tests were performed using a Tinus Olsen Universal Testing Machine having an ultimate load capacity of $900 \mathrm{KN}$ (200 kips). The Universal Testing Machine served both as load cell and as an actuator. However, limitations of the test machine were the need for a wide flanged I-shape reaction beam with a depth of $305 \mathrm{~mm}$ (12 inch) to support the beam specimen during testing. A special spreader plate was designed to load the test beams at the desired points as shown in figure 5 .

\subsection{Theoretical basis}

4.2a Force transfer at the interface of the CFRP strips and the steel beam elements: An important factor for increasing the flexural strength of the beams is to ensure that the CFRP strips and the steel beam act as one composite member. For the member to act in a composite

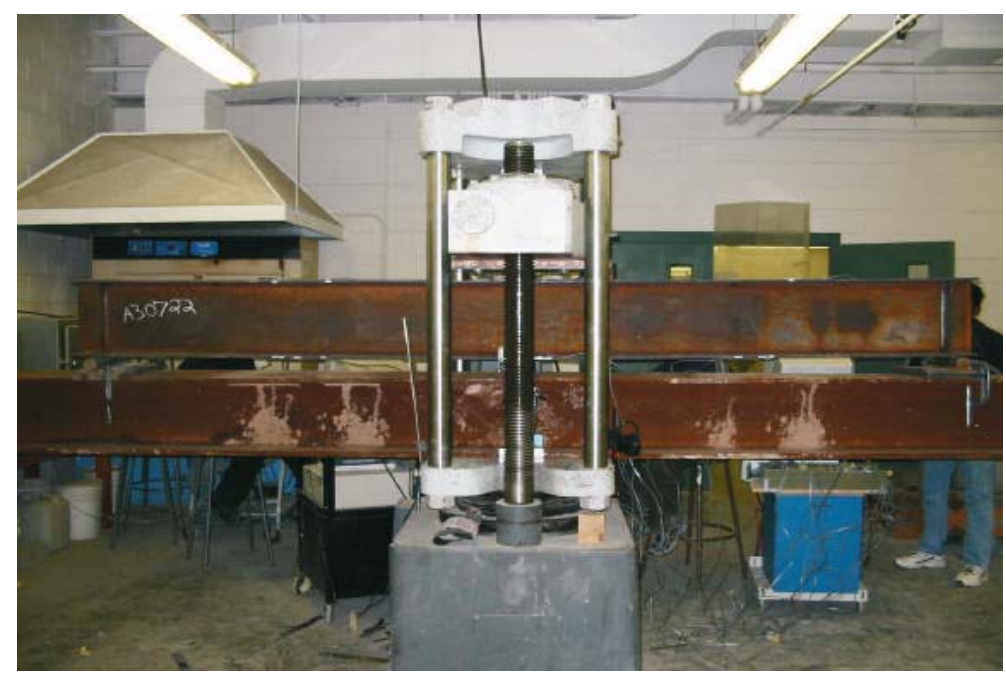

Figure 5. The test set-up. 
manner, the epoxy adhesive used to bond the CFRP strips to the steel beam must be capable of transferring the horizontal shear at the interface, which is equal to the tensile force produced in the CFRP plates at the time of failure for the moment failure beams. The maximum possible tensile force in the CFRP laminate was determined by assuming the bending stresses to be equal to the ultimate tensile strength acting over the entire cross-sectional area of the CFRP plate. The tensile force had to be transferred to the steel section over the length of the section from zero bending moment to the section having maximum bending moment. With four point loading of the beams, the length available to develop this force was from the support point to the loading point (approximately $1.27 \mathrm{~m}$ ). To determine if adequate length was available for the epoxy and the CFRP strips used, the required length was estimated using the expression:

$$
l_{d} \geq \frac{\sigma_{f r p} t_{f r p}}{s} .
$$

In this expression $l_{d}$ is the required development length, $\sigma_{f r p}$ is the tensile strength of CFRP strips $(2,690 \mathrm{MPa}), t_{f r p}$ is the thickness of the CFRP strips $(1.4 \mathrm{~mm})$ and $s$ is the bond strength of the epoxy (12.8 MPa). The expression (equation 1) gives a required development length of $294 \mathrm{~mm}$, which is much less than the provided development length of $1.27 \mathrm{~m}$. Consequently, failure at the interface of the steel with the CFRP was not expected.

\subsection{Ultimate moment}

The width-to-thickness ratios of the section elements, also known as element slenderness, for the moment failure beams were designed to be well within the limits specified in the American Institute of Steel Construction Specifications (AISC-LRFD). Therefore, no local web or local buckling of the flanges was expected for the test beams. Also, the compression flange of the beam was designed to be laterally braced at the loading points.

Elastic behaviour of beams comprised of two materials is quite simple to predict using properties of the transformed section. In attempting to calculate the plastic moment strength of the strengthened flexural members, it was assumed that the bending stresses in the CFRP reached the ultimate tensile stress while the plastic neutral axis (PNA) remained in the web, but moved closer to the tension flange. The total compressive force in the steel section was set equal to the total tensile force in the section of steel below the plastic neutral axis, and the tensile force in the CFRP strips. This force equilibrium requirement revealed that the plastic neutral axis is confined to remain in the web of the flexural test beam. Subsequent to determining the precise location of the PNA, the areas of each element in the section and the corresponding forces were estimated. The respective moment arms from the plastic neutral axis were computed to determine the plastic moment strength of the flexural beams strengthened with CFRP. The plastic moment strength of the strengthened section was theoretically calculated to have a $30 \%$ increase in strength over the plastic moment strength of the bare beam.

\subsection{The ultimate shear strength}

Web slenderness, i.e. the ratio of web height to web thickness, controls the mode of shear failure in steel beams. Failure due to shear can occur in three possible modes (Salmon \& Johnson 1996): (i) Web yielding, (ii) Inelastic web buckling, (iii) Elastic web buckling.

The greatest shear strength is available when yielding of the web occurs and the least shear strength is available when buckling of the elastic web is in control. The slenderness ratio for 
the web of the shear failure beams in this study was large enough to cause buckling of the elastic web.

The loads on the shear failure beams were designed to fail the beams well below the loads that would induce plastic behaviour in both the flange and the web. When the beam behaves in an elastic manner, it is assumed that an elastic analysis using properties of the transformed section can be used without causing appreciable error. A transformed section was developed by applying the modular ratio to thickness of the CFRP strips that were fixed to the web and concurrently obtaining an equivalent thickness of the steel web. With an increase in thickness of the web, the transformed section had a web slenderness ratio in a range that indicated the equivalent failure mode to be yielding. An increase of $26 \%$ in the shear strength was predicted for the shear strengthened beams using this approach. However, a more detailed analysis is essential with adequate consideration of sandwiched panel effect and shear buckling behaviour of the web having properties related to equivalent sandwiched plate.

\section{The test results}

\subsection{The moment failure beams}

A summary of the strengths for the moment failure beams is provided in table 1 . The control beam was labelled as ' $\mathrm{MC}$ ' and the strengthened beams were labelled as 'MS'. The control beam is considered to have failed when the deflections becomes very large with no appreciable increase in moment strength. This type of behaviour is expected with the formation of a plastic hinge. The control beam failed at a load that was $18 \%$ greater than the load predicted by AISC-LRFD. Furthermore, it is interesting to note from this test that the AISC-LRFD specifications underestimate the plastic moment strength of such beams by a small margin. However, this may not be practically relevant primarily because the excessive deflections would prevent the use of this extra margin of strength except in seismic applications.

Both the strengthened beams failed at a load of $461 \mathrm{kN}$. It appeared that the two beams failed due to lateral-torsional buckling. The beams failed at a load that exceeded the load estimated $(446 \mathrm{kN})$ using the AISC-LRFD by only $3 \%$. Failure of the flexure strengthened beams happened in an explosive manner with tensile rupture of the CFRP strips occurring at first followed by bond failure at the CFRP-steel interface. This mode of failure caused the CFRP strips to fly out as narrow, but long pieces, at a great velocity parallel to the axis of the beam. A typical failure mode of the flexure failure beams is shown in figure 6 .

\subsection{Shear failure beams}

A summary of the shear strengths for the shear failure beams is provided in table 2 . The control beam was labelled as 'SC' and the strengthened beams were labelled as 'SS'. The

Table 1. Moment strength summary.

\begin{tabular}{lcccccc}
\hline Specimen & $\begin{array}{c}\text { AISC-LRFD } \\
\text { Load } \\
\text { beam }\end{array}$ & $\begin{array}{c}\text { AISC-LRFD } \\
\text { Moment } \\
\text { strength } \\
(\mathrm{kN}-\mathrm{m})\end{array}$ & $\begin{array}{c}\text { AISC-LRFD } \\
\text { Strength } \\
\text { increase } \\
\%\end{array}$ & $\begin{array}{c}\text { Test load } \\
(\mathrm{kN})\end{array}$ & $\begin{array}{c}\text { Moment } \\
\text { strength } \\
(\mathrm{kN} * \mathrm{~m})\end{array}$ & $\begin{array}{c}\text { Apparent } \\
\text { strength } \\
\text { increase } \\
\%\end{array}$ \\
\hline MC & 342 & 216 & - & $403 \cdot 5$ & $255 \cdot 6$ & - \\
MS1 & 446 & 283 & 30 & 460.4 & 291.6 & $14 \cdot 1$ \\
MS2 & 446 & 283 & 30 & 461.9 & 292.6 & 14.5 \\
\hline
\end{tabular}




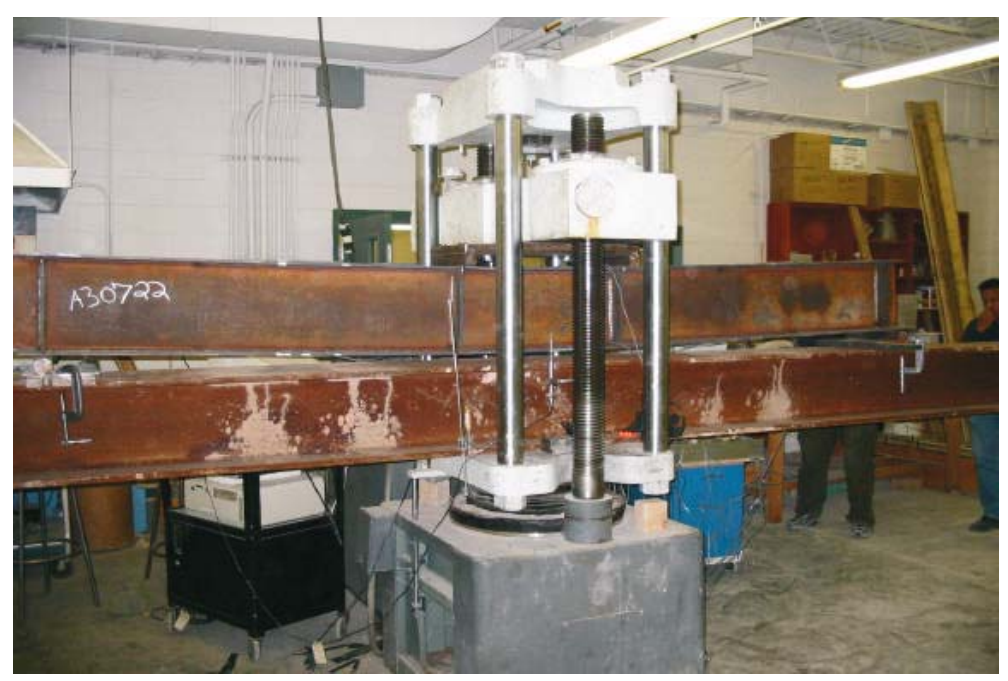

Figure 6. Typical failure of flexure failure beam.

control beam (SC) and beam SS2 failed by web shear buckling, which is classified in this context as a classic web plate buckling failure. The failure load of the control beam was by elastic web buckling, while the web of the shear strengthened beam appeared to have initially yielding culminating in failure by inelastic web buckling. Failure of the beam SS1 was quite unique. The web of the shear failure beams was made of sheet steel metal that was available in $3.05 \mathrm{~m}$ standard widths. Since the beams were a total of $3.35 \mathrm{~m}$ in length, the web was butt jointed at a point about $0.3 \mathrm{~m}$ from the end of the member. The weld essentially failed during the test causing the web to rip open at the joint followed by buckling of the web. This failure of the steel web caused the beam to fail prematurely. Of course, the beam was expected to fail at a larger load capacity. The failure load obtained for this beam test is not considered to be a true representation of the shear strength of the SS1 beam, but certainly greater than the predicted load. A typical failure mode of the shear failure beams is shown in figure 7 after the test was complete and some of the FRP strips were physically peeled. Failure of all the three beams occurred gradually, similar to ductile failure. It was possible to sustain the load for a short time period even after the initiation of buckling of the web.

By using the simplified theoretical approach described earlier, an increase in shear strength of $52 \%$ was predicted (the predicted failure load of $286 \mathrm{kN}$ ). Beam SS2 failed at a load of

Table 2. Shear strength summary (*failed prematurely by steel web tearing at the butt joint).

\begin{tabular}{lcccccc}
\hline & $\begin{array}{c}\text { AISC-LRFD } \\
\text { Load } \\
(\mathrm{kN})\end{array}$ & $\begin{array}{c}\text { AISC-LRFD } \\
\text { Shear } \\
\text { strength } \\
(\mathrm{kN})\end{array}$ & $\begin{array}{c}\text { AISC-LRFD } \\
\text { Strength } \\
\text { increase } \\
\%\end{array}$ & $\begin{array}{c}\text { Test load } \\
(\mathrm{kN})\end{array}$ & $\begin{array}{c}\text { Shear } \\
\text { strength } \\
(\mathrm{kN})\end{array}$ & $\begin{array}{c}\text { Apparent } \\
\text { strength } \\
\text { increase } \\
\%\end{array}$ \\
\hline SC & 176 & 88 & - & $356 \cdot 7$ & 178 & - \\
SS1 & 286 & 143 & 62 & $412 \cdot 3$ & $206^{*}$ & NA \\
SS2 & 286 & 143 & 62 & $449 \cdot 3$ & 225 & 26 \\
\hline
\end{tabular}




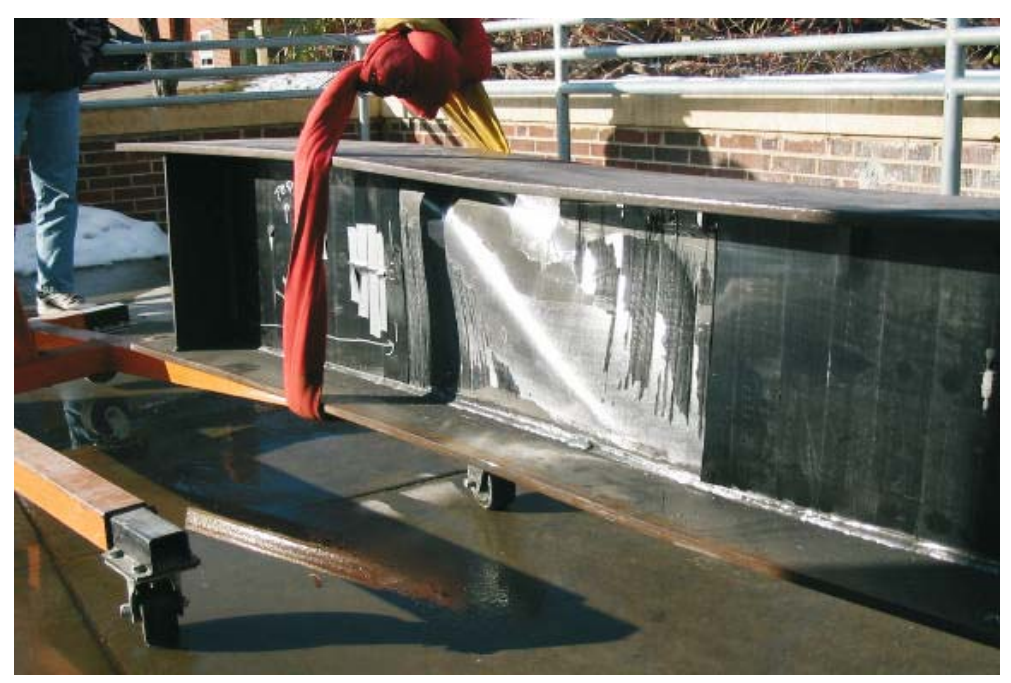

Figure 7. Typical failure of shear failure beams.

$449 \mathrm{kN}$, which is significantly greater than the predicted load. Also, the test beams revealed that the AISC-LRFD specifications grossly underestimates the shear strength of such built-up steel beams.

\section{Conclusions}

In this paper a succinct summary of the results and findings of an experimental investigation of the possibility of strengthening steel beams for the purpose of enhancing their flexural strength and/or shear strength is presented. The key findings of this study are:

(i) It was possible to achieve a theoretical increase in flexural strength of $30 \%$ for the two steel beams strengthened with CFRP. Failure of the CFRP flexure strengthened steel beams was sudden and explosive.

(ii) Theoretical shear strengthening of about $62 \%$ was easily achieved by attaching CFRP strips to the web of the steel beams. The failure of the shear strengthened steel beam was gradual when compared to the flexure strengthened steel beams.

(iii) The successful strengthening of steel beams (for both flexure and shear) shown in this study identifies the need for a more comprehensive and systematic study on intrinsic strengthening mechanisms contributing to the strength of the steel beams.

(iv) The AISC-LRFD specifications for the determination of plastic moment strength and shear strength of the built-up steel beams underestimates the strength by a large margin.

(v) Shear strengthening of about 25 to $39 \%$ is easily achieved by attaching CFRP strips to the web of the steel beams. Failure of a shear strengthened steel beam is observingly gradual when compared to that of a flexure strengthened steel beam.

This research was made possible through funding provided by the National Science Foundation [EPSCoR Grant \#EPS-0091948], State of South Dakota, and the Nelson Research Grant. The authors gratefully acknowledge the agencies for their support. 


\section{References}

Ammar N 1996 Rehabilitation of steel bridge girders with graphite pultrusion (CCM report 96-26). Newark, DE, USA: University of Delaware Center for Composite Materials, University of Delaware pp 126

ASTM Standard E8-01 2001 Standard test methods for tension testing of metallic materials. ASTM

Karbhari V M, Shulley S B 1995 Use of composites for rehabilitation of steel structuresDetermination of bond durability. J. Mater. Civil Eng. 7(4): 239-245

Memmott J 2007 Highway bridges in the United States: An overview (BTS special Report). Tech. rep., Bureau of Transportation Statistics, US Department of Transportation September 2007

Miller T C, Chajes M J, Mertz D R, Hastings J N 2001 Strengthening of a steel bridge girder using CFRP plates. J. Bridge Eng. 6(6): 514-522

Miller T C 2000 The Rehabilitation of steel bridge girders using advanced composite materials. Newark, DE, USA: Master's thesis, University of Delaware, pp 139

Salmon C G, Johnson J E 1996 Steel structures: Design and behaviour, 4th ed. New York: HarperCollins College Publishers, pp 1024

Tavakkolizadeh M, Saadatmanesh H 2003 Strengthening of steel-concrete composite girders using carbon fibre reinforced polymers sheets. J. Struct. Eng., ASCE 129: 30-39

West T D 2001 Enhancement to the bond between advanced composite materials and steel for bridge rehabilitation (CCM report 2001-04). Newark: DE, USA, University of Delaware Center for Composite Materials, University of Delaware, pp 226 